\title{
Locating the probable ignition source in fire expertise
}

\author{
Gheorghe Daniel Florea ${ }^{1 *}$, Nicolae Ioan Vlasin ${ }^{1}$ \\ ${ }^{1}$ National Institute for Research \& Development in Mine Safety and Protection to Explosion- \\ INSEMEX Petrosani, 32-34 G-ral. V. Milea Street, Romania
}

\begin{abstract}
An important aspect in elucidating the causes of fire events occurence, is the identification of the initial outbreak following on-site investigations. Based on the information resulting from the event footprint (observed thermal and dynamic effects) in correlation with the results obtained in the laboratory tests on the collected samples, as well as the possible generating scenarios of the event, the most probable sources of ignition can be identified. The research team must thoroughly analyze all elements of thermal, mechanical, electrical, radiation, chemical, etc. which may have been present or incidents in the initial outbreak.

The computerized fire simulation software will also be used to verify possible scenarios with geometry modeling, combustible / flammable properties of the real case elements, as well as the location of the ignition source, following that the dynamics and propagation directions of simulated fire to be consistent with the case under consideration.
\end{abstract}

\section{Introduction}

One of the activities carried out by the National Institute for Research \& Development INSEMEX Petrosani, with great importance for the Romanian society, is the elucidation of the causes that led to the production of events resulting in losses of human lives and / or material damages, generated by solid or liquid flammable substances, whether or not mixed with air. Based on the information collected from the site by the research team, during the on-site investigations, the institute can carry out computerized simulations of the events, either explosions or fires, simulations that are very useful in analyzing the scenarios and hypotheses elaborated, contributing to consolidating the conclusions regarding the causes of the event's occurrence and its mechanism.

\section{On-site research}

Reports at the scene of fire events involves examining all the elements related to the fire. The practice is similar to the forensic examination, in that the area must be kept intact and all the elements that were the basis of the event should be collected and analyzed. In order

\footnotetext{
* Corresponding author: daniel.florea@insemex.ro
} 
to establish the origin of the initial outbreak, the research includes a strict study of the place where there is massive damage caused by the fire combustion. $[1,3,8]$.

However, in order to effectively examine and evaluate such an event, it is necessary that the research team should have a thorough knowledge of the chemistry and behavior of the fire and its effects.

\subsection{Determining the location of the fire and the cause of the fire}

In order to determine the cause of the fire and the circumstances in which the fire initially started, the on-site research team must establish where the first combustion process was initiated and at the same time find indications regarding the first ignited material, the source that produced the initiation and the circumstances that allowed the event to occur.

Specifying the accurate position of the initial outbreak must be achieved by judicious interpretation of the fire imprint, collaborated with the action of the factors that influence the unfolding of the combustion processes and the propagation of the combustion in the specific situation of the case, how the fire evolved in time and space, the directions and the ways through which they propagated until they covered the entire affected area, so that, going through the opposite direction, to locate the respective trails where the combustion processes started. In general, the initial outbreak shows the traces of a stronger thermal demands [2,7].

The following activities are carried out:

- each low point of fire combustion is analyzed under the aspect of transmitting the combustion from it, by establishing the predominant direction of combustion and the combustion surfaces that could be ignited from this point, to form a fire;

- after analyzing all the low points, the general mark of the fire is studied in order to make the model according to which it is considered that the fire has evolved, is taken into account the action of external factors (wind direction, air currents, basket effect) to determine the effect that could have influence on the development of the fire;

- the conclusions resulting from the study of each combustion point are evaluated in correlation with the general impression and with the evolution mode in the developed phase;

- they are looking for the causes that could have started the fire, in all the low burning points that could constitute, probably place of origin; if none of the low points of combustion could have constituted the place of origin, the research team must consider other possibilities to initiate the fire combustion, at other levels of the investigated space.

\subsection{Classification of ignition sources}

The cause of the fires is the heat energy provided by the ignition source of the flammable / combustible environment. The action of the ignition source on the flammable / combustible environment can be direct or indirect.

The sources of fire ignition may be present / frequent or may occur in rare or very rare situations.

By their nature, the sources of the fire ignition are classified into the following groups: a. Ignition sources with flame

In this category are included fires due to flame ignition sources, also known as "open flame", mostly: matches, candles, fires voluntarily ignited but escaped from control, cutting and oxyacetylene welding devices, thermal devices.

The flame represents a mass of gases emitting electromagnetic radiation as a result of exothermic reactions that produce a rapid increase in temperature. Even very small flames are among the most efficient sources of ignition [4-6]. 
One property of the flame is the rapid increase in temperature, usually up to about $1000^{\circ} \mathrm{C}$. Exceptions are the "cold flames" of some hydrocarbons, which can give certain luminescence at temperatures between $200^{\circ} \mathrm{C}-400^{\circ} \mathrm{C}$, due to intermediate oxidation reactions (aldehydes, ketones), without temperature increases [9].

b. Ignition sources of thermic nature:

Incandescent bodies - Contact between substances and combustible materials with incandescent bodies can cause fires. In incandescent form metals may be present during hot casting or processing, the wood burning, the coal burning, the heat from the ash thrown, the cigarette lit, the red stove pipe, the electric grids etc. The matches and cigarette buds, thrown on fields, in areas, in feed stores, in cereal stores, in deposits with combustible and flammable products, in dangerous sections in fires, on flammable substances and lightly combustible materials, etc., are causes frequent fires.

Heat from the thermal effect of the electric current - lighting and power installations using insulated conductors and electrical cables for long overloads (overload fuses) are heated, can ignite and constitute efficient sources of ignition of combustible materials if they are in direct contact with these.

c. Ignition sources of electric nature:

Spark and electric arc - This is another common cause of fire. The electrical spark is produced at the short and transient piercing of an insulating layer of air or gas, between two electrodes. The spark is basically a short circuit between the electrodes, between two uninsulated conductors or between two contacts. The electric arc is a continuous discharge between two electrodes under voltage. The arc emits strong thermal radiation at very high temperatures (around $3000^{\circ} \mathrm{C}$ ), it is produced and maintained at high voltages and sometimes at low voltages. Sparks have a very short duration of action and can only ignite explosive or highly flammable mixtures, while the electric arc ignites all nearby combustible objects, melts metal conductors, destroys even ceramic insulators or other materials of this kind.

Static electricity - Appears during the technological processes due to friction, it accumulates on the component parts of mechanisms and machines in general, plastic pipes, individual protective equipment, creates an electric field which can produce discharges. By electrification, high potentials are form. If they exceed $300 \mathrm{~V}$, they produce sparks that ignite benzene, at $1000 \mathrm{~V}$ gasoline, at $3000 \mathrm{~V}$ almost all combustible gases, and at $5000 \mathrm{~V}$ most of the combustible dusts ignite. The value of electrical loads depends on a number of external factors such as pressure, humidity and air temperature. As the temperature and humidity rise, the electrostatic loads are reduced. At a temperature of over $45^{\circ} \mathrm{C}$ and a humidity of over $85 \% \mathrm{Rh}$, the electrostatic loads no longer accumulate.

d. Ignition sources of mechanical nature

This category includes mechanically generated sparks. These mechanically generated sparks occur during the friction, impact or abrasion processes that underlie the crushing of solids. The particles separate from the solid, due to the action of mechanical efforts that provide the energy needed to overcome the cohesion of the solid. Part of the energy absorbed by the solid, respectively, from the fragments released, is converted into caloric energy, which in the case of the fragments released, given their very low mass, leads to significant increases in their temperature until incandescent. If these particles are made of oxidizable substances, such as iron or steel, higher temperatures can be reached due to oxidation reactions.

e. Ignition sources of chemical, physico - chemical nature

Chemical reactions occur with heat release (exothermic reactions) or with heat consumption (endothermic reactions). During use, handling or storage of substances that come into contact with other substances can react strongly exotherm and cause fires or explosions. 


\section{g. Arson effect:}

An equivalence can be made between the term "arson" and the term "intentional fire", which can be defined as: ignition with destructive intent of a building, residence, or other property, including its own.

\section{Virtual simulation of ignition source at the compartment level}

In order to explain and interpret the mechanism of a fire, in addition to the reviewed data (photo, video, written documents existing in the file, etc.), a software package is used to perform computer simulations, package composed of the Fire Dynamic Simulator application called through the Pyrosim interface and the Smokeview software for threedimensional visualization of the results $[10,11]$.

In order to evaluate the environmental conditions that led to the occurrence of a fire in a compartment, it is essential to estimate the temperatures of the hot gases and their arrangement in space and time. By this estimation can be explained the different stages of the fire, in its extension from a compartment to a whole platform.

The virtual simulations of a fire targets, first of all, the estimation of the temperatures that appeared near the source of ignition, the possibility of ignition, starting from the presumed source of combustible materials and the propagation of the flame front to the neighboring rooms, where there were deposits with important support in fire development. Depending on the resulting temperatures, the propagation of the flame front, the amount of heat released and the movement of the hot gases can be approximated.

\subsection{Fire development inside a compartment}

Initially, the fire in a compartment can be treated as a free, singular combustion, resulting from a source of ignition, in an environment with normal oxygen level. The development of the fire depends on the amount of heat released by the fuel mass, the volume of the compartment, its ventilation, the amount of fuel existing inside the compartment.

In the tested scenario, the supposed ignition source is placed at the level of the electrical installation on an object made out of combustible material, a component of the electrical installation that supplies a hot water boiler with electricity. At the level of the wall there are stored cardboard boxes containing textile materials with different properties (cotton, wool and synthetic) as well as boxes with paper, as seen in figure 1 .
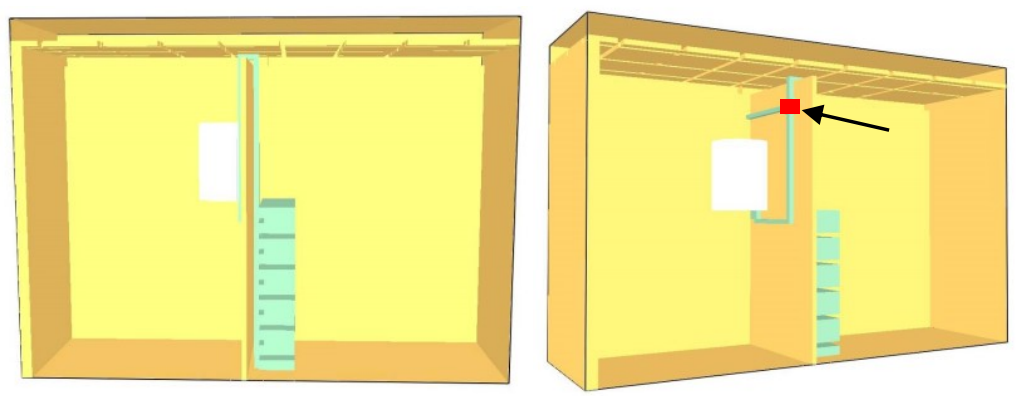

Fig. 1. Room geometry and ignition source.

The compartment has a length of 5.2 meters a width of 2 meters and a height of 3.4 meters resulting in a volume of 35.36 cubic meters $\left[\mathrm{m}^{3}\right]$. 
The computerized analysis required segmentation of the model's calculation domain into 3 discretization networks using cells of size $0.1 \times 0.1 \times 0.1 \mathrm{~m}$, suitable to obtain a good accuracy for the output data. Thus resulted in a number of 107.520 cells for the discretization network, the simulation duration was 500 seconds.

Atmospheric conditions fits within normal limits:

- atmospheric conditions frame into the normal ones, namely:

- ambient temperature inside of stand and warehouse: $5^{\circ} \mathrm{C}$;

- ambient oxygen mass fraction: $0.23237 \mathrm{~kg} / \mathrm{kg}$;

- atmospheric pressure: $1.01325 \times 105 \mathrm{~Pa}$;

- relative humidity: $70 \%$.

The characteristics [12] of the materials used are presented in Table 1.

Table 1. Materials characteristics.

\begin{tabular}{|c|c|c|c|c|c|c|}
\hline Material & $\begin{array}{l}\text { Density } \\
{\left[\mathrm{kg} / \mathrm{m}^{3}\right]}\end{array}$ & $\begin{array}{l}\text { Specific heat } \\
{\left[\mathbf{k J}^{\prime} /\left(\mathbf{k g}^{0} \mathbf{K}\right]\right.}\end{array}$ & $\begin{array}{c}\text { Thermal } \\
\text { conductivity } \\
{\left[\mathbf{W} /\left(\mathbf{m}^{0} \mathbf{K}\right)\right]}\end{array}$ & $\begin{array}{l}\text { Heat } \\
\text { release } \\
{[\mathrm{kJ} / \mathrm{kg}]}\end{array}$ & $\begin{array}{c}\text { Heat } \\
\text { release per } \\
\text { unit area } \\
{\left[\mathrm{kW} / \mathrm{m}^{2}\right]}\end{array}$ & $\begin{array}{c}\text { Ignition } \\
\text { temperature } \\
{\left[{ }^{\circ} \mathrm{C}\right]}\end{array}$ \\
\hline Wood & 640 & 2,85 & 0,14 & 17000 & 200 & 240 \\
\hline Paper & 790 & 1,336 & 0,05 & 18400 & 170 & $218-246$ \\
\hline PVC & 1380 & $\begin{array}{c}1,29\left(23^{\circ} \mathrm{C}\right) \\
1,35\left(50^{\circ} \mathrm{C}\right) \\
1,47\left(100^{\circ} \mathrm{C}\right) \\
1,59\left(150^{\circ} \mathrm{C}\right)\end{array}$ & $\begin{array}{c}0,192\left(23^{\circ} \mathrm{C}\right) \\
0,175\left(50^{\circ} \mathrm{C}\right) \\
0,147\left(100^{\circ} \mathrm{C}\right) \\
0,134\left(150^{\circ} \mathrm{C}\right)\end{array}$ & 20000 & 312 & 390 \\
\hline Plastic & 950 & 1,67 & 0,18 & 31000 & 400 & 349 \\
\hline Textiles & 240 & 1,357 & 0,1 & 17000 & 250 & 220 \\
\hline
\end{tabular}

\subsection{Ignition source}

The ignition source initiates the combustion process in an interval that represents the sum of the pyrolysis time of the solid and the induction time of the gas phase:

$$
t i g=t p y+t i n
$$

As the flow velocity increases, the heat flux over the surface increases and consequently, the time required for heating and pyrolysis of the solid decreases [13]. On the other hand, an increase in gas velocity will result in a decrease in the residence time of the flow. This phenomenon will delay the start of the chemical reaction, or even prevent its initiation.

The presence of a driven (pilot) ignition will affect the ignition process by locally reducing the induction time. The heating of the solid will be the dominant mechanism in the ignition process, with a low gas flow rate and a normal oxygen concentration.

The source of ignition and the propagation of the flame in the compartment are represented in the following sequence of images. 

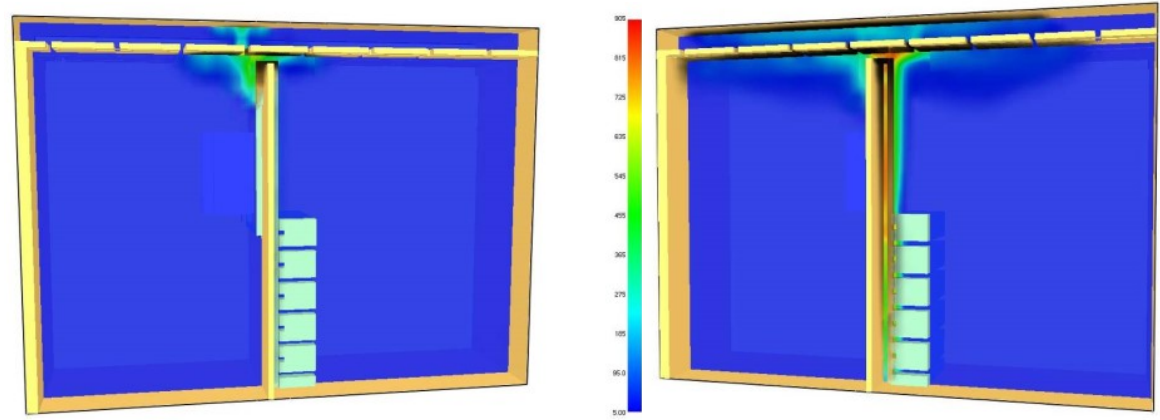

Fig. 2. Ignition and propagation of the flame in the neighboring room.
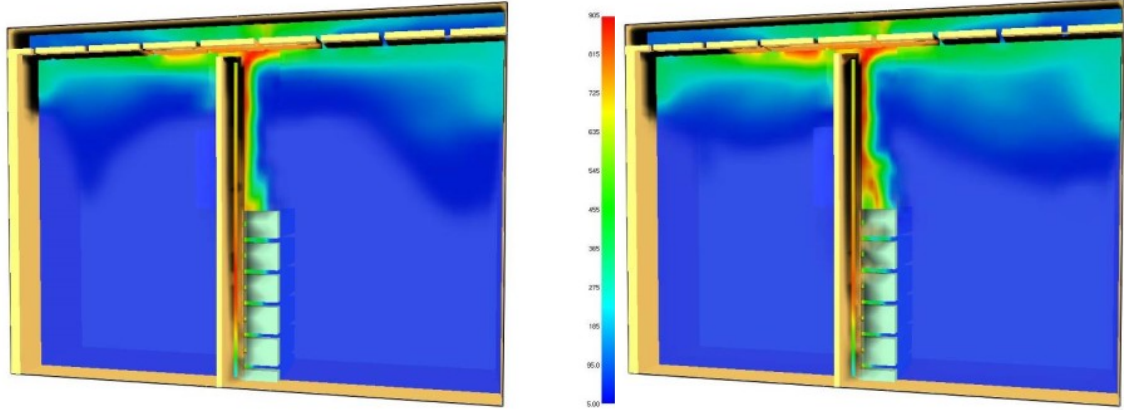

Fig. 3. Fire of combustible materials and local development of the fire.

The initial focus of the fire generated high temperatures of $905^{\circ} \mathrm{C}$ and smoke that penetrated through gaps, into the free space between the false ceiling and the real ceiling of the construction.

\subsection{Flame propagation}

The spread of flame on solid surfaces can be seen as a continuous process of driven ignition. In order for the flame to spread, a sufficient amount of heat from the flame or other heat sources must be transferred in front of it. The vaporized fuel is then diffused and transported convective off the surface, where it mixes with the oxidants forming the flammable mixture in the area in front of the flame, to be ignited by it.

\section{Conclusions}

The virtual simulations of such high-risk events offer possibilities for estimating the risks regarding the safety and health of the personnel, the environment, constructions, material damage etc.

The fire may occur due to the appearance of the ignition source, generated by the deterioration of the electrical contacts related to the electrical circuit of the power supply of the boiler, which caused the ignition of the plastic material of the insulation used, of the branching dose, of the layers of plastic material (the outer shell) of the input / output electrical cables related to the branching dose.

Permanent and long-term use of the boiler, in an environment with high relative humidity, required and damaged the electrical contacts from the branch / connection dose, 
and by accentuating the degradation by corrosion and oxidation of the contacts, the heat released by the Joule-Lenz effect at the passing of the electric current through imperfect contacts.

\section{Acknowledgements}

This paper was developed within the Nucleu-Programme, carried out with the support of Romanian Ministry of Research and Innovation, project no. PN-19-21-01-05, project title: Fundamental research and computer simulations on the initiation of explosive gas mixtures by potential sources of ignition of a different nature (in Romanian: Cercetari fundamentale si simulari computerizate privind initierea amestecurilor gazoase explozive prin surse potentiale de aprindere de natura diferita).

\section{References}

1. M. C. Suvar, N. I. Vlasin, V. M. Pasculescu, E. Ghicioi; -Proceedings of 16th International Multidisciplinary Scientific GeoConference SGEM 2016, Informatics, Geoinformatics and Remote Sensing- 1, 25-32 (2016)

2. D. Pasculescu, L. Lupu, V. M. Pasculescu, I. Inisconi, M. C. Suvar, Environmental Engineering and Management Journal, 11, 1267-1271, (2012)

3. M. Prodan, E. Ghicioi, I. Nalboc, A. Szollosi-Mota, 7 th International Multidisciplinary Symposium "Universitaria Simpro 2016" - 199-244, (2016)

4. A. B. Șimon- Marinică, E. Ghicioi, N. I. Vlasin, M. C. Șuvar, G. D. Florea, 19th International Multidisciplinary Scientific GeoConference - SGEM 2019 Conference Proceedings, 1165- 1171 (2019)

5. D. Pasculescu, L. Pana, V. M. Pasculescu, F. Deliu, Mining of Mineral Deposits, 13 (2), 1-16, (2019)

6. V. M. Pasculescu, N. I. Vlasin, E. Ghicioi, G. D. Florea, M.C. Suvar, Environmental Engineering and Management Journal, 18 (4), 889-900, (2019)

7. M. C. Suvar, D. Cioclea, V. Arad, C. Lupu, N. I. Vlasin, Environmental Engineering and Management Journal, 16, 1373-1381, (2017)

8. V. M. Pasculescu, M. C. Suvar, N. I. Vlasin, G. A. Gaman, D. Florea, Proceedings of 15th SGEM GeoConference on Informatics, Geoinformatics and Remote Sensing, 1, 77-84. (2015)

9. N. I. Vlasin, C. Lupu, E. Ghicioi, E. Ghicioi, C. Tomescu, Environmental Engineering and Management Journal, 13, 1439-1444. (2014)

10. G. H. Yeoh, K.K Yuen Computational Fluid Dynamics in Fire Engineering Theory, Modelling and Practice(Oxford, United Kingdom, 2008)

11. F. Wayme, N. Gomeau, Incendie sen milieu confine, (2007)

12. J. G. Quintiere and A. S. Rangwala. Fire and Materials, 28, 387-402, (2004)

13. Pyrosim User Manual, 2014, Available on http://www.thunderheadeng.com/pyrosim/resources/ 